\title{
Screening and Partial Purification of Hydroxamate Type Siderophore from Pseudomonas sp.
}

\author{
Kuppuswamy Kavitha', Arumugam Suganya ${ }^{1}$, Kuppusamy Umaa Rani ${ }^{2}$ and \\ Balasubramaniyan Ramesh ${ }^{2 *}$ \\ ${ }^{1}$ Department of Microbiology, Sri Sankara Arts and Science College, Enathur, \\ Kanchipuram - 631561, Tamil Nadu, India \\ ${ }^{2}$ Department of Biotechnology, Sri Sankara Arts and Science College, Enathur, \\ Kanchipuram - 631561, Tamil Nadu, India \\ *Corresponding author
}

\begin{tabular}{|c|c|}
\hline & A B S T R A C T \\
\hline Keywords & \multirow{4}{*}{$\begin{array}{l}\text { The present study document the isolation and enumeration of siderophore } \\
\text { producing microbes from iron contaminated soil. Identification of potential strains } \\
\text { and optimization studies for the production of siderophore was carried out. The } \\
\text { Iron contaminated soil samples were collected from welding shops, factories in } \\
\text { and around Kanchipuram and Thiruvallur. Ten morphologically different strains } \\
\text { (AS1-AS10) were selected for further screening for the production of siderophores } \\
\text { by Ferric Perchlorate Assay. Strain AS- } 6 \text { showed a maximum OD value of } 0.82 \\
\text { and was further identified as Pseudomonas sp and optimization studies were } \\
\text { carried out. Siderophore production was maximum when using Glucose medium, } \\
72 \text { hours of incubation; pH 5.5, } 30^{\circ} \mathrm{C} \text {; Ferric Chloride as additive. The partially } \\
\text { purified siderophore showed good zone of inhibition against water borne } \\
\text { pathogens such as Salmonella, Vibrio, Shigella, and E.coli. }\end{array}$} \\
\hline $\begin{array}{l}\text { Siderophore, } \\
\text { Pseudomonas, } \\
\text { Waterborne } \\
\text { pathogens. }\end{array}$ & \\
\hline Article Info & \\
\hline $\begin{array}{l}\text { Accepted: } \\
\text { 23 August } 2017 \\
\text { Available Online: } \\
\text { 10 September } 2017\end{array}$ & \\
\hline
\end{tabular}

\section{Introduction}

Micro-organisms growing in aerobic conditions need iron for a variety of functions including reduction of oxygen for the synthesis of ATP, for formation of heme and other essential purposes (Neilands, 1995). Siderophore dissolve these ions by chelating as $\mathrm{Fe}^{3+}$ soluble complexes that can be taken by active transport mechanisms. Many siderophore are non-ribosomal peptides (Julie, 1999). Siderophores are defined as relatively low molecular weight, ferric ion specific chelating agents synthesized by bacteria and fungi growing under low ionic stress. Strategies other than siderophores to enhance iron solubility and uptake are the acidification of the surrounding or the extra cellular reduction of $\mathrm{Fe}^{+}$into the more soluble $\mathrm{Fe}^{+}$ ions. Examples of siderophore produced by various bacteria and fungi are Ferrochrome (Ustilago sphaerogena), Enterobactin (Escherichia coli), Mycobactin (Mycobacterium species), Enterobactin and Bacillibactin (Bacillus subtilis), Ferrioxamine B (Streptomyces pilosus), Fusaninine C 
(Fusarium roseum), Yersiniobactin (Yersinia pestis); Pseudobactin (Pseudomonas aeruginosa) etc.

Siderophore producing algae are also reported. These are Anabena species which facilitate iron uptake (Balagurunathan and Radha Krishnan 2007). Carboxylates earlier called complex ones are produced by bacteria (Rhizobium and Staphylococcus strains) and Fungi (Dave and Dube, 2000). Carboxylate nature of siderophore are detected by Vogel's chemicals test (Vogel, 1987) and further confirmation by spectrometric assay (Shenker et al., 1992).

Hydroxamate siderophores are present in various soils and they are also produced in aquatic environments. Burton et al., (1954) had shown the importance of siderophores in maintaining the balance in mixed microbial population in the soil and that some microbes synthesize siderophores, while others use them without synthesizing any. Desferrioxamine has also been used to remove vanadium. In rats desferrioxamine reduced the vanadium content in kidney by $20 \%$ in lungs by $25 \%$ and in liver by $26 \%$ when administered at $100 \mu \mathrm{mol} \mathrm{kg}^{-1}$ following a dose of $5 \mu$ mole $\mathrm{kg}^{-1}$ of $\mathrm{Na}_{48}$ $\mathrm{VO}_{3}$. Both urinary and fecal excretion increased at this dose (Hansen et al., 1984). Desferrioxamine has proved successful in the treatment of dialysis encephalopathy, which is a major complication of long term dialysis. It is caused by the accumulation of aluminum in the brain from dialysis water supply. Siderophores from Klebsiella pneumoniae has been used as an antimalarial agent (Gysin et al., 1991) and in cosmetics as deodorants (Johnson et al., 2003).

Siderophores plays a main role in the biodegradation of petroleum hydrocarbon in marine ecosystems by facilitating microbial acquisition of iron. Barbean et al., (2000) isolated oil degrading marine bacterium
Marinobacter hydrocarbonclasticus. It produces a siderophores called Petrobactin that readily undergoes a light mediated decarboxylated reaction. Petrobactin is the first structurally characterized siderophores produced by the known hydrocarbon degrading marine bacterium. Pseudomonas fluorescens $\mathrm{AH} 2$ on inhibition of pathogenic bacteria in fish was studied under iron rich and iron limited condition (Gram et al., 1999). Neilands (1995) reported that desferrioxamine B produced by Streptomyces pilosus is advocated for the removal of excess iron resulting from the supportive therapy for thalassemia.

The present study aims at isolation and enumeration of siderophore producing microbes from iron contaminated soil. Attempts were also made in identification of potential strains and optimization studies for the production of siderophore.

\section{Materials and Methods}

\section{Sample collection}

Iron contaminated soils samples were collected from welding workshops, factories in and around Kanchipuram and Thiruvallur. Soil samples were collected by using sterile spatula and polythene cover and transported to the laboratory (Braud et al., 2009).

\section{Isolation of bacteria from soil samples}

One gram of soil sample was weighed and mixed with $99 \mathrm{ml}$ distilled water. Then the sample was serially diluted up to $10^{-8}$ dilution about $0.1 \mathrm{ml}$ of aliquot from $10^{-2}$ to $10^{-8}$ dilutions were taken and platted in triplicate on sterile nutrient agar plate and one plate was kept as control. All the plates were incubated at $28^{\circ} \mathrm{C}$ for 48 hours. After incubation, plates were observed for presence of colonies, which were purified and streaked on nutrient agar plates (Cappuccino, 1999). 
Screening for siderophore producing microorganisms

Ten morphologically different strains were subjected to screening for the production of siderophores by ferric perchlorate assay as recommended by Payne, 1994. The maximum optical density to the culture supernatant indicated the level of siderophores.

All the 10 strains were subjected to ferric perchloric acid assay consisted in mixing $0.5 \mathrm{ml}$ of culture supernatant or a suitable dilution there with $2.5 \mathrm{ml}$ of $5 \mathrm{mM}$ ferric chloride was dissolved in $0.1 \mathrm{M}$ perchloric acid in a cuvette followed by using sterile medium as the blank then the cuvette was subjected to calorimetric analysis.

\section{Identification of potential strain}

The potential strain AS6 was identified up to genus level by studying phenotypic characters like gram staining, motility and biochemical characteristics like oxidase, catalase, IMVIC, urease, nitrate reduction and sugar fermentation tests. The methods described by Microbiology: A laboratory Manual by (Cappuccino 2013) was followed for all the procedures. All these results were compared with Bergey's manual of determinative bacteriology to determine the genus.

Based upon the expressed phenotypic characters, the potential strain AS6 was identified as Pseudomonas sp.

\section{Optimization studies}

Optimization studies were carried out by changing various parameters for siderophore production. Different parameters studied were incubation period, $\mathrm{pH}$, media namely Glucose medium, King's B medium, Glutamic medium and Succinate medium (Patel et al., 2009). The presence of siderophores was confirmed by using TLC. Culture supernatant was spotted on silica gel plates and spots were allowed to dry. The plates were then developed using Butanol: Acetic acid: Water (12:3:5) solvent system until the solvent front reaches the top of the plate. Plates were then dried and sprayed with $0.1 \mathrm{M} \mathrm{FeCl}$ in $0.1 \mathrm{~N}$ $\mathrm{HCl}$ (Patel et al., 2009). The protein fraction from culture broth was purified using SG 25 gel column.

The column was equilibrated with $50 \mathrm{mM}$ potassium phosphate buffer ( $\mathrm{pH}$ 2.0). The sample was loaded and the unbound fractions were washed off with phosphoric acid. The bound sample was eluted using $0.1 \mathrm{M}$ phosphate buffer ( $\mathrm{pH}$ 7.0). The fractions were monitored by taking absorbance at $380 \mathrm{~nm}$ on UV Spectrophotometer (Patel et al., 2009).

\section{Determination of antimicrobial activity of siderophore}

Muller Hinton agar plates were prepared and the water borne pathogens such as Salmonella $s p$, Shigella sp, E. coli sp, Klebsiella sp, Vibrio $s p$ were swabbed on the plate by using sterile cotton swabs. Then wells were cut through the gel and the purified iron binding protein was inoculated into wells. The plates were incubated at $28^{\circ} \mathrm{C}$ for $24 \mathrm{hrs}$ for formation of zone of inhibition (Patel et al., 2009).

\section{Results and Discussion}

\section{Isolation of bacteria from soil samples}

Bacterial population in nutrient agar plates was estimated as $136 \times 10^{5} \mathrm{CFU} / \mathrm{gram}$, $83 \times 10^{5} \mathrm{CFU} / \mathrm{gram}, 46 \times 10^{5} \mathrm{CFU} / \mathrm{gram}$ for soil sample I, II and III respectively. From the plates 10 morphologically different strains (AS1-AS10). All the 10 strains were subjected to screening for the production of siderophores by Ferric perchlorate assay as recommended by Payne, 1994. The maximum optical density to the culture supernatant 
indicated the presence of siderophores. Strain AS-6 showed maximum OD value of 0.82 and was selected for further identification and optimization studies.

\section{Identification of potential strain}

The potential strain AS6 was identified based upon the expressed phenotypic characters, the potential strain AS7 was tentatively identified as Pseudomonas sp (Fig. 1).

\section{Optimization studies}

The siderophore production was maximum when using Glucose medium (OD: 0.85). The effect of incubation period on siderophore production was maximum at 72 hours with absorbance of 0.98 and the maximum at $\mathrm{pH}$ and temperature $5.5(\mathrm{OD} 1.20) ; 30^{\circ} \mathrm{C}(\mathrm{OD}$ : $1.19)$ respectively.

Finally, maximum siderophore production was observed when using Ferric Chloride as additive (OD: 1.40).

Detection of siderophore by thin layer chromatography

Siderophores were confirmed by using TLC (Fig. 2).

Fig.1 Colony morphology of Pseudomonas species on Nutrient Agar plates

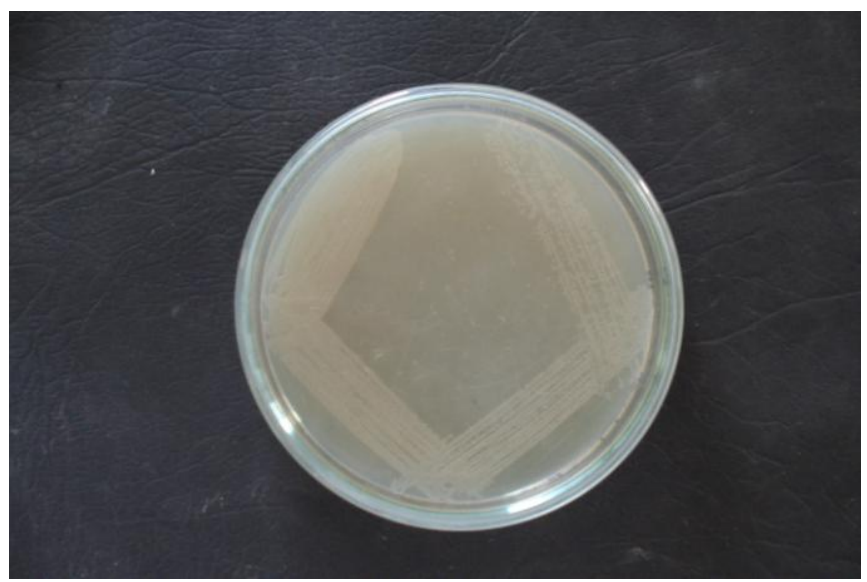

Fig.2 Detection of siderophore by thin layer chromatography

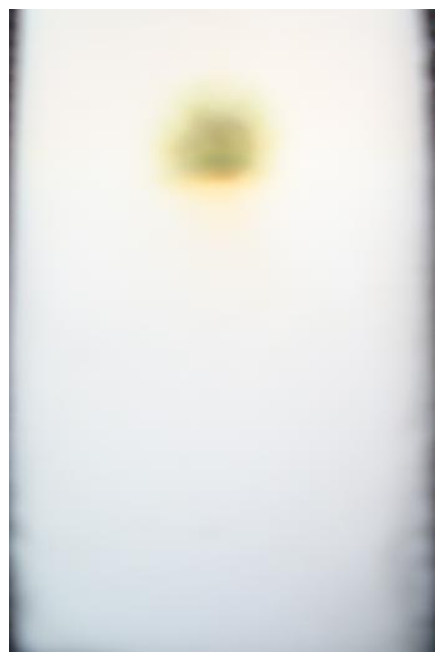


Fig.3 Elution profile of siderophore separation by column chromatography

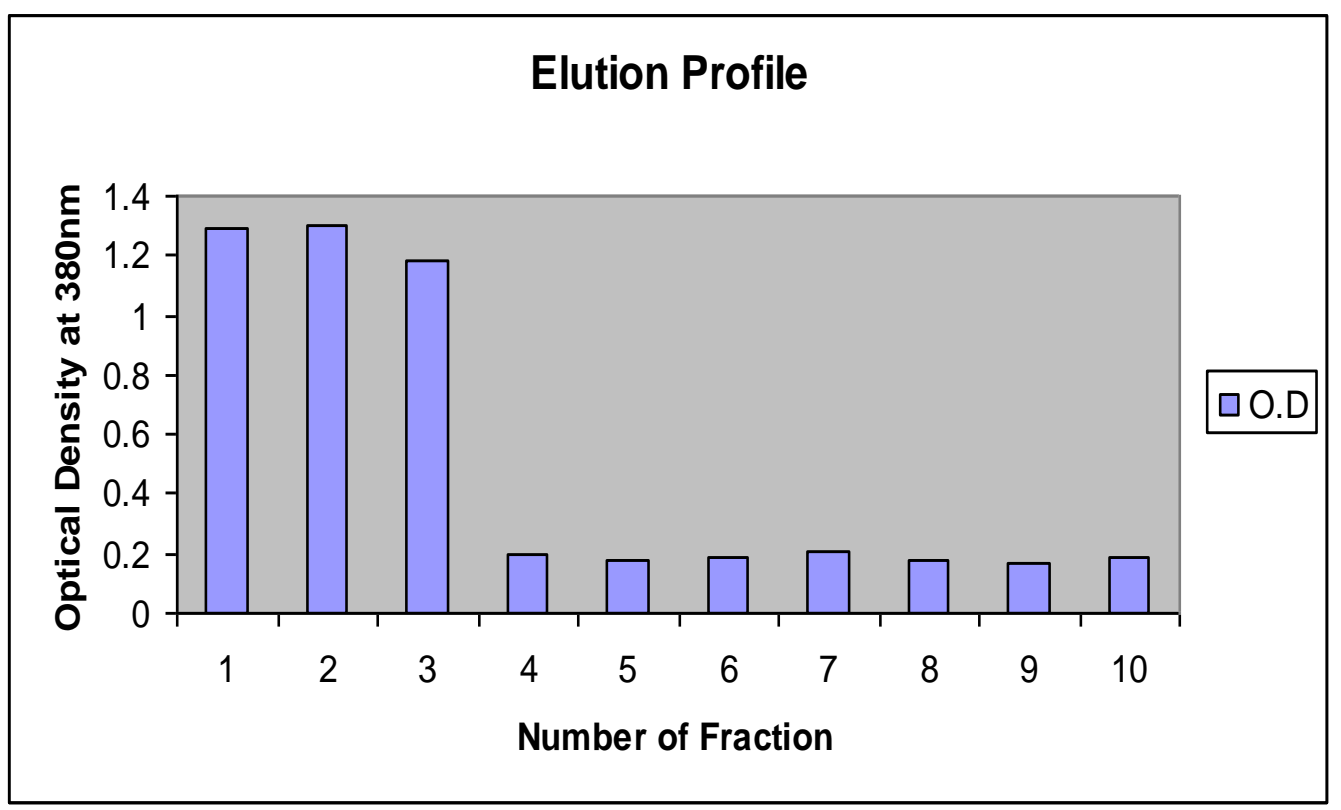

Fig.4 Determination of antimicrobial activity of siderophore

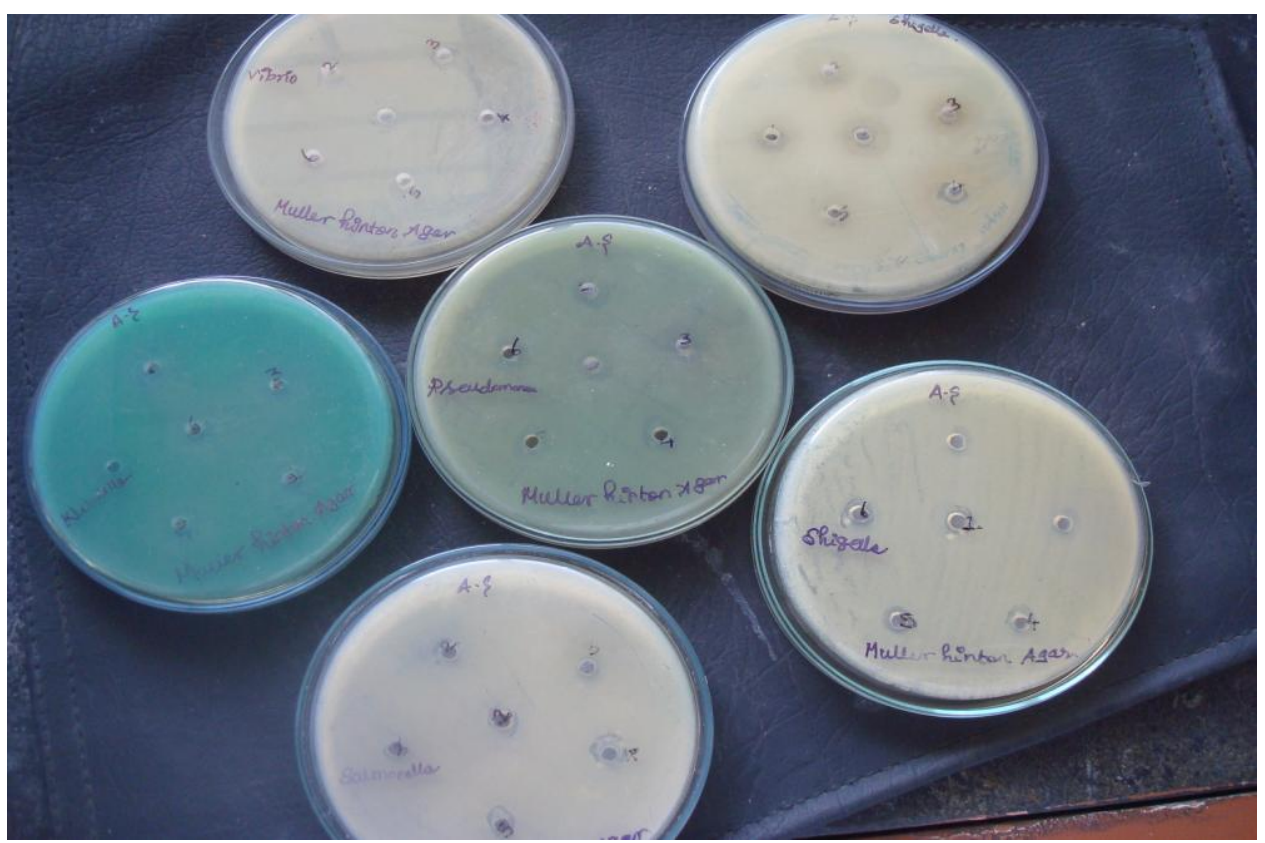

Purification of protein fraction by column chromatography

Chromatography was performed using Sephadex G25 gel column (Patel et al., 2009).
The results clearly indicate that the Fractions 1,2 and 3 showed high optical density at 380 $\mathrm{nm}$ and were pooled and used as single active fraction for further antimicrobial activity studies (Fig. 3). 


\section{Determination of Antimicrobial activity of siderophore}

Antimicrobial activity of active fraction was assed against water borne pathogens such as Salmonella sp, Shigella sp, E. coli, Klebsiella $s p$, Vibrio $s p$. (Fig. 4). The active fraction showed good zone of inhibition against water borne pathogens such as Salmonella, Vibrio, Shigella and E. coli in Muller Hinton agar plates.

The study reports the isolation and enumeration of siderophore producing microbes from iron contaminated soil. It is concluded that the iron contaminated soil samples are good source for the isolation of siderophore producing microbes and also indicates that these siderophores can be used against pathogenic bacteria.

\section{Acknowledgement}

The authors thank the management of Sri Sankara arts and Science College for providing the laboratory facilities. A special thanks to Dr. K. R. Venkatasen for his encouragement and support during the study.

\section{References}

Balagurunathan, R., and M. Radhakrishnan. 2007. Microbial siderophores- gateway for iron removal. Envis Centre Newsletter, 5:7-9.

Cappuccino G. James, and Natalie Sherman. 1999. Microbiology: A Laboratory Manual. The Pearson Benjamin Cummings Publication Company Inc., California. $10^{\text {th }}$ Edition.

Gram, L., 1995. Influence of substrate on Siderophore production by fish spoilage bacteria. Journal of Microbiological Methods, 25:199-205.

Holt G. John, Noel R. Krieg, Peter H. A. Sneath, James T. Staley and Stanley T. Williams, 1994. Bergey's Manual of Determinative Bacteriology. Williams and Wilkins, A Wolters kluwer. $9^{\text {th }}$ Edition.

Neilands, J. B., 1995. Siderophores: structure and function of microbial iron transport compounds. Journal of Biological Chemistry, 270(45):26723-26726.

Parker, D. L., G. Sposito, and B. M. Tebo. 2004. Manganese (III) binding to a pyroverdiene siderophore produced by manganese (II)oxidizing bacterium. Geochemical ET Cosmochimica Acta, 68(23):4809-4820.

Patel Anil, K., Maroti K. Deshattiwar, Bhushan L. Chaudhry and Sudhir B. Chincholkar. 2009. Production, Purification and Chemical Characterization of a chatecholate type siderophore from potent probiotic strain of Bacillus sp. Bioresource Technology. 100: 368-373.

Trskova, R., P. Rychlovsky, I. Nemcova, and A. Jegorov. 1995. Development of a spectrophotometric determination of siderophores using flow injection analysis. Talanta, 42(6):837-843.

Vache, A., D. A. A. Mossel, and H. Leclerc. 1997. Antimicrobial activity among Pseudomonas and related strains of mineral water origin. Journal of Applied Microbiology, 83:652658.

Villegas, M. E. D., P. Villa, and A. Frias. 2002. Evaluation of the siderophores production by Pseudomonas aeruginosa PSS. Reveiw. Latinoam. Microbio, 44(3-4):112-117.

Wilson, M. K., R. J. Abergel, K. N. Raymond, J. E. L. Arceneaux, and B. R. Byers. 2006. Siderophores of Bacillus anthracis, Bacillus cereus, and Bacillus thuringiensis. Biochemical and Biophysical Research communication, 348:320-325.

\section{How to cite this article:}

Kuppuswamy Kavitha, Arumugam Suganya, Kuppusamy Umaa Rani and Balasubramaniyan Ramesh. 2017. Screening and Partial Purification of Hydroxamate Type Siderophore from Pseudomonas sp. Int.J.Curr.Microbiol.App.Sci. 6(9): 2380-2385.

doi: https://doi.org/10.20546/ijcmas.2017.609.291 